\title{
Direito e Poder: Hobbes e a dissolução do Estado
}

\author{
Maria Isabel Limongi \\ UFPR \\ belimongi@yahoo.com.br
}

resumo Partindo da idéia de que, a partir da Maquiavel, a relação entre direito e poder tornou-se problemática, procura-se tratar aqui do modo como Hobbes lidou com esse problema. De um lado, ele separou essas duas instâncias, por ele entendidas enquanto duas modalidades diferentes de relações entre os homens. Por outro, ele apoiou tais relações umas sobre as outras, na constituição do Estado. Quer-se mostrar que, longe de incidir numa incoerência, a diferença e ao mesmo tempo o apoio recíproco entre relações de direito e de poder constituem o modo específico com que Hobbes respondeu aos desafio posto por Maquiavel e o eixo a partir do qual ele pensou o problema fundamental da duração do Estado no tempo.

palavras-chave Hobbes; direito; poder; Estado

É um ponto central na filosofia de Hobbes a distinção entre as relações de puro poder e as relações de direito e dever.

A distinção está implicada na definição hobbesiana do direito natural: "o direito de natureza (...) é a liberdade que cada homem possui de usar seu próprio poder, da maneira que quiser, para a preservação de sua própria natureza, ou seja, de sua vida" (HOBBES, 1985, p. 189; 1974, p. 82). ${ }^{1}$ Consistindo o direito na liberdade de uso do poder, tal direito permanece o mesmo, seja o poder maior ou menor. É o que Hobbes esclarece, quando, após definir a liberdade em que consiste o direito natural como ausência de impedimentos externos, precisa: tais impedimentos "muitas vezes tiram parte do poder que cada um tem de fazer o que 
quer, mas não podem obstar a que use o poder que lhe resta, conforme seu julgamento e razão lhe ditarem" (HOBBES, 1985, p. 189; 1974, p. 82). O esclarecimento visa indicar o sentido preciso em que se deve compreender que um direito é restringido ou cancelado: não pela oposição de um outro poder (pois o poder cancela apenas um outro poder), mas por meio de uma obrigação, cancelando a liberdade de usar o poder como se queira, na qual consiste propriamente o direito.

Daí decorre a distinção entre o escravo e o servo. O primeiro, "guardado na prisão ou a ferros (...), não tem obrigação alguma, e pode, sem injustiça, destruir suas cadeias ou prisão e matar ou levar cativo seu senhor", ao passo que o servo, não estando submetido à prisão ou a ferros, se vê contudo obrigado por contrato a "não fugir nem praticar violência contra seu senhor" (HOBBES, 1985, p. 255; 1974, p. 128). Os vínculos de direitos e dever, que ligam o servo ao seu senhor, têm, portanto, uma natureza distinta das relações de poder, sobre as quais se assentam a escravidão. Tais vínculos se estabelecem por contrato, não se reduzindo, por essa razão, a uma relação de força e poder.

As obrigações, como dirá Hobbes a respeito da lei civil, são como "cadeias artificiais" (artificial chains) e consistem num tipo especial de "laço" ou "vínculo" (bound) entre os homens (HOBBES, 1985, pp. 263, 192). Trata-se de vínculos jurídicos, instituídos voluntaria e artificialmente por contrato, relativamente aos quais os termos justiça e injustiça ganham sentido. Tais são os vínculos civis, que contrastam com o modo das relações naturais entre os homens, as quais consistem na oposição e composição dos poderes individuais. Pode-se dizer que nossas relações naturais são relações de poder, enquanto que nossos laços civis são laços de dever e obrigação, laços jurídicos, que constituem o Estado e são sustentados por ele.

No modo como Hobbes trabalha essa distinção entre relações de poder e vínculos jurídicos pode-se divisar uma espécie de acerto de contas com Maquiavel, uma vez que, de uma perspectiva hobbesiana, o pensamento político de Maquiavel não teria guardado a distância conveniente - que é para Hobbes uma diferença de natureza - entre relações de direito e relações de poder. É esse o pano de fundo da célebre resposta de Hobbes ao insensato no capítulo 15 do Leviatã, na qual há uma referência implícita a Maquiavel. 
O insensato afirma que a injustiça não existe. E Hobbes precisa em que sentido deve-se entender essa negativa: não que o insensato negue que existam pactos "e que umas vezes eles são desrespeitados e outras são cumpridos, e que seu desrespeito pode ser chamado injustiça, e sua observância justiça”" (HOBBES, 1985, p. 203; 1974, p. 91). Não que o insensato negue a existência de obrigações contratuais. O que o insensato se pergunta é se, sendo o rompimento de uma obrigação conveniente a um homem "numa situação em que lhe permita desprezar, não apenas o ultraje e censuras, mas também o poder dos outros homens", se, nesse caso, este rompimento não seria justo. "O reino de Deus se ganha pela violência" - raciocina o insensato. "E se fosse ganho pela violência injusta? Seria contra a razão assim ganhá-lo, quando daí é impossível que resulte qualquer dano? E se não é contra a razão, não é contra a justiça, caso contrário a justiça não pode ser considerada uma coisa boa" (HOBBES, 1985, p. 203; 1974, p. 91). Ou seja, de acordo com o insensato, havendo o poder de romper uma obrigação, se disso resultar algum benefício (como, por exemplo, a conquista de um reino), os vínculos jurídicos ficam cancelados, deixando de oferecer a medida da justiça.

Esse raciocínio, porém, é segundo Hobbes especioso e requer ser combatido. O que é combatível não é a relação entre justiça e interesse que ele pressupõe e que Hobbes não pretende negar, mas o fato de se fazer a justiça flutuar ao sabor de configurações circunstanciais de poder, desconsiderando, com isso, que ela se segue com necessidade de um ato contratual e pondo a perder a autonomia dos vínculos jurídicos em relação às relações de força e poder. Se não há nenhum poder obstando a não realização de um pacto, pode ser justo, segundo o insensato, não cumpri-lo, de modo que, de acordo com esse raciocínio, os vínculos de obrigação se encontram na dependência e são subsidiários de relações de poder.

Isso vai de encontro à distinção diligentemente construída por Hobbes entre relações de poder e de direito. O poder de fazer algo não implica o direito de fazê-lo, assim como o direito não requer poder para se afirmar - o poder de se apoderar de um reino não implica o direito de fazê-lo, assim como se pode ter o direito a um reino do qual não se tem o poder de conquista. A justiça está fundada sobre contratos e permanece estável relativamente ao ato que a funda, bem como independente das alterações do poder. Pois, a justiça não advém da restrição de um poder, 


\section{4}

e sim de um direito, da liberdade de usar o poder como se quer, ou da obrigação de usá-lo de um certo modo, seja qual for, circunstancialmente, o poder que se tem.

No entanto, embora a distinção de natureza entre esses dois níveis de relações seja cara a Hobbes, sua teoria do Estado estabelece uma relação de co-dependência entre essas instâncias.

$\mathrm{O}$ Estado se define como um poder soberano; mas um poder, que à diferença de todos os outros, é instituído juridicamente por contrato. No capítulo 10 do Leviatã, Hobbes descreve o modo de composição de poder que não aquele que constitui o Estado, em relação ao qual este último ressalta por contraste. Trata-se do poder das facções ou das coligações de facções, constituído não por contrato e mediante o uso da razão, por meio de um cálculo do justo e do injusto, mas a partir das opiniões que os homens têm de seu próprio poder e o dos outros, do valor que atribuem a esses poderes conforme o uso que podem fazer deles e do modo como esses valores são manifestados e adquirem reputação pelos atos de honra. Os homens tendem a compor e opor seus poderes de acordo com as opiniões que fazem do próprio poder relativamente ao dos outros. Este é o modo como naturalmente o poder se compõe. Mas, artificialmente, no Estado, o poder se compõe e se forma por outra via, que lhe assegura precisamente a soberania - a via jurídica do contrato. $\mathrm{O}$ poder do Estado se singulariza, portanto, por ser juridicamente fundado sobre vínculos de obrigação e dever.

Por sua vez, as relações jurídicas se sustentam sobre o poder do Estado, pois, como versa a afirmação bem conhecida de Hobbes, os pactos sem a espada não passam de conversa fiada, palavras vazias. É apenas sob a proteção do poder do Estado que os homens podem criar vínculos jurídicos entre si e calcular suas condutas como um cálculo de direitos e obrigações. O Estado se constitui assim por meio de uma relação de mútua dependência entre direito e poder.

Assim, é como quem joga Hobbes contra si mesmo, que Rousseau, após afirmar enfaticamente no capítulo 3 do livro 1 d' O Contrato Social 
que a força não faz o direito (o que, posto desse modo, é uma afirmação que cabe perfeitamente na boca de Hobbes), contesta a validade de um pacto de submissão e alienação da liberdade, tal como admitido por Grotius e Hobbes com base em um suposto direito do vencedor à vida do vencido. $\mathrm{O}$ direito da conquista, contesta Rousseau, "não tem outro fundamento senão a lei do mais forte" (ROUSSEAU, 2006, p. 17). Ou seja, não é direito algum, mas uma relação de força, uma continuação da condição de guerra, da qual não se deriva direito. Noutros termos: porque a força não faz o direito, o direito não pode ser deduzido da guerra, na qual o que está em jogo são relações de força. Assim, é preciso, segundo Rousseau, não apenas distinguir as relações de direito das relações de poder, como buscar um fundamento puro para o direito (ou para o contrato), evitando que ele se apóie sobre uma relação de poder. Eis como podemos entender o projeto do contratualismo político de Rousseau, nesse ponto profundamente anti-maquiaveliano.

Hobbes, porém, num aparente paradoxo, recusa a identificação maquiaveliana entre direito e poder, ao mesmo tempo em que não hesita em fundar o direito sobre o poder do Estado, e este, por sua vez, sobre um direito. Eis o que Rousseau vê como uma inconsistência. Pode-se, no entanto, dizer que Hobbes busca uma via intermediária entre a de Maquiavel e a de Rousseau. Para ele, o direito não se identifica ao poder, mas nem por isso lhe é contraditório.

Essa via intermediária, longe de consistir numa via paradoxal, numa inconsistência, perfaz o interesse da filosofia política de Hobbes. Não há inconsistência: o contrato fundante do poder do Estado tem uma natureza distinta desse poder; este, por sua vez, em sua natureza própria, se oferece como condição da validade dos contratos (inclusive do que o funda) sem, no entanto, ser parte constitutiva da obrigação. ${ }^{2}$ A distinção entre as relações de poder e de direito não se perdem em função do seu apoio recíproco. Pois, Hobbes concebe a diferença de natureza entre elas de maneira a assegurar sua co-existência, recusando a sua mútua exclusão e permitindo o seu apoio recíproco.

As relações de poder são relações naturais. Assim como os corpos se chocam e compõem e opõem entre si seus movimentos, os homens compõem e opõem os seus poderes. O poder não é simples força física, mas reside numa certa capacidade de se fazer valer e reputar de modo a 
reunir força em torno de si (cf. HOBBES, 1985, cap. 10). Nesse sentido, enquanto reunião de forças, as relações de poder são relações naturais. E, no que são mais do que simples relações de força, ali onde se fundam num universo propriamente humano e social, nas opiniões que os homens têm do próprio poder, do poder dos outros e de seus valores, nesse aspecto também as relações de poder são naturais, porque tais opiniões se formam segundo a experiência e a prudência, formas de pensar que não requerem a intervenção de nenhum artificio, como é o caso da razão que se funda na linguagem, a qual, por sua vez, é uma invenção humana, logo, da ordem do artificio (Cf. HOBBES, 1985, cap. 5). Dessa ordem são as nossas relações jurídicas, que, além de serem racionais e suporem o artifício da linguagem, resultam de um ato voluntário e consistem numa instituição humana, que tem o homem por causa. Ora, natureza e artificio são duas ordens de realidades contínuas e co-existentes. E por isso podem perfeitamente apoiar-se umas sobre as outras. Hobbes recusa assim a via da idealização do direito, que será a de Rousseau e Kant e nisso merece alguma atenção.

Esse tema - a questão da relação de co-existência e dependência recíproca entre direito e poder sem prejuízo da diferença de natureza entre essas instâncias - fica tão mais interessante e promissor quando se observa o modo como Hobbes explora, no seu pensamento político, a tensão que subjaz à correlação entre esses elementos distintos. Pode-se talvez dizer que nessa correlação reside a questão da política para Hobbes, localizando aí o modo propriamente hobbesiano de lidar com o problema, central no pensamento político moderno, da estabilidade das formas políticas e da permanência no tempo das constituições (cf. POCOCK, 1975).

Para Hobbes, a constituição que a ação política deve fazer persistir no tempo não é uma determinada forma de governo, como mostrou Pocock com respeito a seus antecessores e contemporâneos republicanos (cf. POCOCK, 1975), mas o Estado, entendido como um conjunto de relações de direito - as relações de obrigação e direitos que se seguem do pacto civil - que dão sustentação, ao mesmo tempo em que são sustentadas por um poder de fato - ao poder soberano do Estado. Nisso resulta justamente a dificuldade da ação política, qual seja, a de fundar e manter a boa relação entre direito e poder, tal que, na falta de um direito bem constituído não falte poder ao Estado, ou que, inversamente, na falta de 
poder, não lhe falte o direito ao governo. A questão da correlação entre direito e poder nos conduz, assim, a duas temáticas correlatas, a do bom governo e a da dissolução do Estado, das quais trataremos a seguir, de maneira apenas indicativa e de modo algum exaustiva, a título ilustrativo do modo como Hobbes pensa a política nos termos da articulação entre direito e poder.

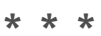

A distinção entre os conceitos de Estado e de governo se permite pensar, na filosofia política de Hobbes, a partir da distinção entre dois tipos de direitos do soberano.

De um lado, há os direitos que se seguem diretamente do pacto de instituição da soberania enquanto um pacto de autorização, isto é, os direitos que se seguem como conseqüência necessária dos termos dessa autorização. Quando a multidão reunida pactua de modo a ceder a um homem ou assembléia de homens o direito de representá-la, ou, o que dá do mesmo, quando autoriza todos os atos desse homem ou assembléia como se fossem seus, ela está, por este mesmo ato através do qual é instituído um poder soberano (soberano porque dispõe da "força e dos recursos de todos" (HOBBES, 1985, p. 228; 1974, p. 110), reconhecendo que este poder não pode: (1) ser transferido para outrem sem seu consentimento; (2) ser confiscado; (3) ser protestado pela minoria uma vez tendo sido declarado pela maioria; (4) ser acusado de injúria; (5) ser punido. No conjunto, tais direitos conferem ao poder soberano um caráter absoluto, posto que juridicamente incontestável, no que concerne ao direito de exercer todos os seus atos. O Estado é esse poder soberano e absoluto na medida em que instituído por e derivado do contrato.

Por outro lado, há os direitos que se derivam da finalidade para a qual foi instituída a soberania em seu caráter absoluto. "Visto que o fim dessa instituição é a paz e a defesa de todos, e visto que quem tem direito a um fim tem direito aos meios" (HOBBES, 1985, p. 232; 1974, p. 113), cabe ao soberano o direito de fazer tudo o que considere necessário à paz e segurança comuns, do que se seguem aqueles direitos que de um modo feliz Yve-Charles Zarka denominou os direitos a posteriori da soberania, em 


\section{8}

contraste com os do primeiro grupo, denominados por ele direitos a priori (Cf. ZARKA, 2000). Tais direitos podem ser ditos a posteriori na medida em que não se deduzem diretamente, como os primeiros, do ato de instituição da soberania, não se seguem diretamente da causa e do princípio gerador da soberania que é o contrato, mas se determinam a partir dos efeitos, isto é, da identificação das conseqüências que se seguem do exercício desses direitos para o estabelecimento e manutenção da paz entre os homens. Assim, são direitos do soberano: (1) ser juiz das doutrinas, no que são favoráveis ou contrárias à paz; (2) definir a propriedade, (4) ser juiz das controvérsias; (5) fazer a guerra e a paz com outros Estados; (6) escolher os magistrados, conselheiros e todos os funcionários; (7) recompensar e castigar; (8) conceder títulos de honra, ordem e dignidade.

Em conjunto, os direitos a posteriori determinam que cabe ao soberano o direito irrestrito a determinados meios de governo, sem os quais ele não se constitui efetivamente como um poder soberano, o que ele é de direito a partir do pacto de sua instituição. Se o soberano não for juiz das doutrinas, se não definir a propriedade, etc., de fato não haverá paz, e os poderes dos indivíduos se oporão uns aos outros, no lugar de se comporem em torno da soberania, como de direito o fazem a partir do pacto civil. Assim, os direitos a posteriori enumerados acima são destacados por Hobbes na medida em que o soberano não pode deixar de exercêlos sem com isso pôr o Estado a perder. O Estado implica, assim, um direito de governo. Este, por sua vez, pode ser entendido como o exercício do direito aos meios que garantem à soberania o poder de fato, capaz de assegurar o seu poder de direito absoluto.

Vale observar a esse respeito que, conforme se lê na introdução ao Leviatã, o homem é considerado por Hobbes o artífice e a matéria do Estado. Ele é artífice na medida em que institui o Estado por contrato; matéria na medida em que o poder do Estado é feito pela composição do poder dos indivíduos que o instituem, o que é ilustrado com perfeição no frontispício da primeira edição inglesa do Leviatã, no qual o Estado é representado por um homem cujo corpo é formado pelos corpos de diversos homens. A materialidade da imagem é irrecusável. O Estado não é apenas uma união das vontades por meio de vínculos jurídicos, mas uma composição de corpos, logo, de forças e poderes. É aí precisamente que a questão do governo se inscreve, na necessidade e na dificuldade de 
articular esses dois aspectos do Estado, na articulação entre o seu direito e o seu poder, pensados por Hobbes de um modo tal que nenhuma dessas instâncias prevalece sobre a outra. Como vimos, o Estado só se constitui enquanto um vínculo jurídico de mando e obediência na medida em que compõe os poderes dos indivíduos num poder soberano. E vice-versa.

O governo pode ser pensado na vertente do poder. Seu papel é o de compor poderes ou evitar que eles se oponham de modo a pôr a soberania a perder. Cabe, assim, à soberania, enquanto uma instância de governo, sustentar o Estado, que é a soberania enquanto conseqüência jurídica do contrato. Pois, ainda que os vínculos jurídicos que compõem o Estado sejam, de direito, relativamente ao ato de sua instituição, eternos, se o Estado não tiver o poder necessário para realizar o fim em vista do qual foi instituído, o pacto de sua instituição torna-se juridicamente nulo: “a obrigação dos súditos para com o soberano dura enquanto, e apenas enquanto, dura também o poder mediante o qual ele é capaz de protegêlo" (HOBBES, 1985, p. 282; 1974, p. 139). Nessa frase, condensa-se toda a dificuldade do governo - a de garantir o poder necessário para a manutenção dos vínculos jurídicos em que consiste o Estado.

Sendo assim, o direito ao governo pode ser bem ou mal exercido, ou, se quisermos, o governo que de direito cabe a soberania, pode de fato ser bom ou mau, a depender de sua capacidade de efetivamente assegurar o fim em vista do qual se exerce, e isso a despeito do direito absoluto que tem a soberania de exercê-lo segundo o seu próprio juízo e critério. Assim, a questão do bom governo ou da prudência política pode ser pensada em termos hobbesianos como a questão da escolha dos meios adequados para que o vínculo de direito das vontades resulte numa composição de fato dos poderes, sem o que o Estado não existe enquanto direito. A questão do bom governo está, assim, diretamente ligada ao problema da dissolução do Estado.

Hobbes distingue dois grupos de "coisas que enfraquecem ou levam à dissolução de um Estado" ou dois grupos de doenças do corpo político (HOBBES, 1985, p. 363; 1974, p. 196). A metáfora do corpo enfermo, 
explorada para designar o Estado em vias de dissolução, indica que a questão se coloca em termos de um processo. Tendo em vista que o direito derivase do contrato, e, relativamente a ele, está de todo presente ou de todo ausente, é pela vertente do poder que dá sustentação ao direito - este sim variável segundo as circunstâncias - que se coloca o problema da dissolução.

De um lado, há as doenças maiores, "aquelas que têm origem numa instituição imperfeita” (HOBBES, 1985, p. 363; 1974, p. 196). A primeira delas está em que o soberano se contente com um poder menor que o necessário para manter a paz e a defesa de todos, ou seja, com um poder menos que absoluto. Hobbes esclarece: não se trata tanto de uma incompreensão acerca da necessidade (no sentido lógico e jurídico) desse poder, ainda que esse possa também ser o caso, mas sobretudo de uma incapacidade de fazer valer seu direito absoluto ao governo, diante de outros poderes que se opõem ao e limitam o seu. Em se tratando de uma doença de nascença, de uma "procriação imperfeita”, o que está em jogo é menos uma incapacidade de governo ou falta de prudência política e mais uma incapacidade da soberania em se fazer reconhecer e se impor, desde o princípio (tomado no sentido lógico), no seu direito ao governo.

O segundo grupo dessas doenças constitutivas se deriva "do veneno das doutrinas sediciosas" (HOBBES, 1985, p. 365; 1974, p. 197), as quais Hobbes passa então a enumerar. O que essas doutrinas têm em comum, o seu caráter sedicioso reside em que elas desviam os homens do raciocínio jurídico que constitui o Estado e em vista do qual cada um dá sua adesão racional a ele, favorecendo, no lugar disso, a constituição de poderes paralelos e a divisão do poder do Estado em facções. Assim, se a primeira doença maior está em que o soberano admita algum tipo de limitação ao seu poder, de direito absoluto, a segunda está em que os súditos não consintam com esse direito. Nos dois casos, o que está em jogo é uma má compreensão do direito, levando à insuficiência do poder.

Há, além dessas, as doenças menores, "não tão graves", tais como a de não conseguir dos súditos o dinheiro requerido para os gastos públicos, o qual, fazendo-se necessário, acaba por ser arrancado por meios violentos. Há dois problemas aí. Primeiro, o de não conseguir o dinheiro, o que é uma limitação do poder. Segundo, o de consegui-lo através da violência. Hobbes não diz explicitamente, mas o problema aí envolvido é que a violência (ainda que justa, posto que as ações da soberania não podem de 
direito ser contestadas) favorece a rebelião, que, mesmo sendo inicialmente injusta, pode de fato retirar do Estado o poder de assegurar a paz e a defesa de seus súditos, tornando-se, assim, num segundo momento, legítima, visto que, como mencionado, o Estado que não é capaz de assegurar a paz e a defesa de seus súditos não é de direito um Estado.

Há também as doenças relacionadas à constituição de poderes paralelos ao do Estado, como a que se segue da concentração do seu tesouro nas mãos de alguns "por meio de monopólios ou contratos de renda pública" ou a que decorre da grande "popularidade de um súdito poderoso", ou ainda "da grandeza imoderada de uma cidade" ou do "grande número de corporações" (HOBBES, 1985, pp. 374-5; 1974, p. 202). E, por fim, as doenças relativas a questões de política externa, como as que decorrem do alargamento excessivo dos domínios do Estado ou da vitória de um inimigo externo.

Tais doenças, ditas menores, concernem a um mau governo, a má gestão dos direitos a posteriori da soberania. As doenças maiores, por sua vez, dizem respeito à má compreensão da natureza do Estado e de seus direitos a priori. Nos dois casos, porém, o problema que leva à dissolução do Estado concerne ao governo e à dificuldade de constituir a soberania como um poder de fato, além de direito. $\mathrm{O}$ problema se põe, pois, a posteriori, uma vez que "pela natureza de sua instituição", ou seja, a priori, relativamente ao pacto de instituição da soberania, os Estados "estão destinados a viver tanto tempo quanto a humanidade, ou quanto as leis de natureza, ou quanto a própria justiça que lhes dá vida" (HOBBES, 1985, p. $363 ; 1974$, p. 196). Os Estados são a priori eternos. A posteriori, porém, é possível que eles não consigam assegurar o poder necessário para sustentar de fato o sistema de relações jurídicas em que eles consistem, para o que, entre outras coisas, e de maneira crucial, se requer a devida compreensão de sua natureza jurídica e dos seus direitos.

O que é difícil de assegurar é, portanto, a convergência material das vontades garantindo a composição efetiva do poder, por trás do vínculo formal das vontades formando o Estado por contrato. ${ }^{3}$ Assegurar essa convergência é algo que está na dependência de um bom governo. Em vista dos perigos que o governo tem que evitar e os tipos de doença contra as quais deve se assegurar, pode-se dizer que o governo tem basicamente duas tarefas fundamentais. De um lado, governar as opiniões, 
(donde a recorrência do tema do controle das doutrinas por parte do Estado e da educação para a vida civil, para a qual Hobbes pensa ser o seu Leviatã um instrumento adequado e útil), pelo que se evitam as doenças maiores. Do outro, regular as relações sociais de poder, impedindo a constituição de poderes paralelos que se sobreponham ao poder do Estado, pelo que se combatem as doenças menores.

Assim, a questão da dissolução do Estado é o horizonte a partir do qual se põe o problema do governo e da ação política propriamente dita, a qual cabe a tarefa de evitar essa dissolução e garantir a permanência do Estado no tempo. A questão da dissolução, por sua vez, se constrói sobre o pano de fundo da distinção e mútua dependência das relações de direto e poder, o que indica que nessa correlação está o cerne do pensamento político de Hobbes e que, longe de constituir uma inconsistência, nela reside a singularidade deste pensamento diante do desafio lançado por Maquiavel, quando este embaralhou os limites tradicionalmente estabelecidos entre essas duas instâncias.

\footnotetext{
${ }^{1}$ Ao longo de todo o texto, tomamos o Leviatã como obra de referência e apoio (sempre citado primeiramente no original e, em seguida, na tradução utilizada, quando for o caso), deixando de lado as questões concernentes as diferenças e semelhanças entre a teoria política aí exposta e aquelas expostas nas obras políticas anteriores, os Elementos da Lei e o Do Cidadão.

2 Diferentemente de certos comentadores, como Gauthier, entendemos que a obrigação contratual tem para Hobbes um fundamento estritamente formal, que reside na exigência de não contradição entre os signos que denotam uma vontade no ato contratual. $\mathrm{O}$ poder do Estado, ou, mais precisamente, o medo da punição que dele decorre não é parte da obrigação, como se fosse preciso acrescentar ao seu fundamento formal um fundamento material, que estaria no interesse efetivo de cumprir o pacto, como quer Gauthier (Cf. GAUTHIER, 1969, p. 60 e ss.). O poder do Estado é sem dúvida uma condição material da obrigação. Mas não porque o medo de um poder coercitivo, ao oferecer aos contratantes um motivo para cumprir seus contratos, complemente o que antes era uma obrigação simplesmente formal e, nessa medida, sem força para obrigar. O fundamento da obrigação é formal - o compromisso com a palavra dada ou o compromisso racional de não contradição entre os signos da vontade. Ocorre, porém, que a validade formal dos contratos depende de uma condição material - o poder punitivo do Estado, que, ao oferecer a cada contratante a garantia de que o outro cumprirá sua parte, confere coerência às vontades expressas no contrato, fazendo com que seus signos possam remeter a uma vontade possível. O poder punitivo do Estado assegura deste modo a validade formal dos contratos, sem se constituir, contudo, como um fundamento adicional da obrigação.
}

doispontos, Curitiba, São Carlos, vol. 6, n. 3 - especial, p.181-193, abril, 2009 
3 Trata-se de um problema intrínseco à razão, tal como Hobbes a concebe, que parte de definições e se desenvolve como cálculo formal de signos, e nesse sentido independe do jogo das concepções mentais, mas que não pode deixar de ser preenchida por essas últimas, sob o risco de se tornar vazia.

\section{Referências bibliográficas}

Gauthier, D. P. (1969) The Logic of Leviathan, Oxford: Oxford University Press.

Hobbes, T. (1985). Leviathan, Londres: Penguin Books.

Hobbes, T. (1974). Leviatã, São Paulo: Abril Cultural.

Pocock, J. G. A. (1975). The machiavellian moment, Princeton: Princeton University Press.

Rousseau, J-J. (2006) O Contrato Social. São Paulo: Martins Fontes.

Zarka,Y-C. (2000) "Do direito de punir", Filosofia Política, nova série, vol. 5. 